\title{
Los Sitios Web de las Universidades Privadas de Santiago en el marco de la Sociedad de la Información ${ }^{1}$
}

\author{
Emilio Torres Rojas*
}

\begin{abstract}
Resumen
En un escenario cambiante, compuesto por nuevas casas de estudio, diversificación de las alternativas académicas y por nuevas generaciones de jóvenes, socializados en las tecnologías de la información, los recursos técnicos y la necesidad de las universidades de diferenciarse y constituirse como un opción atractiva, se constata una considerable expansión en la utilización de recursos tecnológicos como los sitios y plataformas web tanto a nivel internacional como local.

Esta tendencia que había sido adoptada primero por importantes universidades a nivel mundial y posteriormente por las principales casas de estudio tradicionales en Chile, se ha constituido actualmente como un recurso importante para la difusión y promoción de todas las casas de estudios superiores, particularmente las del sector privado que no pueden apelar a una tradición como las universidades más antiguas del sistema. Pero a la vez, constituyen un recurso que se integra progresivamente a los procesos centrales de producción de conocimiento, enseñanza-aprendizaje y articulación de redes así como los de índole administrativas de las universidades.

El presente artículo describe características generales presentes en los sitios web de las universidades privadas del Área Metropolitana de Santiago, comparando un conjunto de dimensiones que constituyen distinciones comunicativas oficiales. A partir de ello se derivan algunas tendencias predominantes observables en la actualidad en dichos sitios, que dan cuenta de formas adaptativas homogéneas pero de baja intensidad respecto de los desafíos de la sociedad de la información.
\end{abstract}

Palabras clave: Sociedad de la Información, universidades y comunicación

1 El presente artículo forma parte del Proyecto de investigación "Acreditación Institucional y Adaptaciones del Sistema Universitario en la Sociedad del Conocimiento. Una caracterización Cualitativa y Cuantitativa en Universidades Privadas Chilenas", que realiza el autor con el auspicio de los fondos concursables de Investigación Básica y Aplicada de la Universidad Central de Chile.

* Sociólogo, Universidad de Chile, Magíster en Ciencias Sociales, Universidad de Chile. DEA en Psicología y Educación, Universidad de Granada. Dr. (c) Universidad de Granada 
Los Sitios Web de las Universidades Privadas de Santiago en el marco de la Sociedad de la Información

\begin{abstract}
In a changing environment, comprising new houses of study, diverse academic options for new generations of young people socialized in information technology, technical resources and the need for universities to differentiate and become an attractive option, it is observed a considerable expansion in the use of technological resources such as web sites and platforms both internationally and locally.

This trend, which had first been adopted by leading universities worldwide and subsequently by the major houses of traditional study in Chile, has today become a major resource for the dissemination and promotion of all households of higher education, particularly those in the private area which cannot appeal to a tradition as the oldest universities in the system. But then again, they are a resource that progressively integrates the core processes of knowledge production, teaching learning and networking articulation as well as the administrative nature of universities.

This article describes the general characteristics found in the websites of private universities in the metropolitan area of Santiago, comparing a set of dimensions that constitute official communication distinctions. From the results, some observable trends prevailing in those sites are derived, which accounts for homogeneous adaptive forms but of low intensity concerning the challenges of the information society.
\end{abstract}

Key words: Information Society, universities and communication 


\section{Era de la información y nuevos escenarios para la Universidad}

Durante las últimas décadas, el mundo ha experimentando transformaciones tan radicales que prácticamente no existen áreas de la sociedad que no se hayan visto afectadas y la educación por supuesto no es la excepción. A pesar de la diversidad de perspectivas que se vienen sucediendo para interpretar los procesos de cambio, los especialistas no llegan a ponerse de acuerdo en las causas y consecuencias de tales mutaciones.

Entre los planteamientos que han recibido mayor atención se encuentran los del sociólogo español Manuel Castells, quien después de una larga trayectoria intelectual, ha reavivado el debate en los últimos años con su monumental obra "La Era de la Información" y un conjunto de artículos y conferencias donde ha continuado desarrollando su propuesta teórica. En lo substancial la tesis de Castells afirma que está surgiendo, a nivel mundial, bajo distintas formas según las particularidades socioculturales e institucionales, una estructura social asociada a un nuevo modo de desarrollo que denomina "informacionalismo", que reestructuró el capitalismo y comenzó a trasformar los procesos de producción, la experiencia humana y el poder, como ejes centrales del acontecer social. En este nuevo modo de producción informacional, la fuente de productividad radica fundamentalmente en la tecnología, en la generación de conocimiento, las formas de procesamiento de la información y la comunicación de símbolos (Castells, 1997).

Las características básicas de este nuevo paradigma relacionado con: la alta capacidad de penetración de las nuevas tecnologías de la información, que tienden a modelar crecientemente la existencia individual; la lógica de interconexión de todos los sistemas que utilizan las nuevas tecnologías y que han determinado el surgimiento de una nueva morfología de interrelaciones denominada "sociedad red" y la alta flexibilidad que implican capacidades de adaptabilidad de reversión y reestructuración sin 
Los Sitios Web de las Universidades Privadas de Santiago en el marco de la Sociedad de la Información

precedentes, se torna crucial en un modelo de cambio continuo y de fluidez organizativa.

La integración de estos rasgos comienza a generar transformaciones históricas de gran magnitud y profundidad que implican adaptaciones y transformaciones radicales, no sólo en la esfera económica, académica y tecnológica donde se originaron, sino que en todos los ámbitos institucionales de las sociedades contemporáneas y ha generado fuerzas que conllevan cambios conductuales profundos en los individuos que realizan su acción en ellas. De allí que Castells afirme que desde una perspectiva histórica, la instauración de la sociedad red representa un cambio cualitativo de la experiencia humana y lejos de ser el fin de la historia, es su comienzo, pues se trata de una nueva era de la información marcada por la autonomía de la cultura frente a las bases materiales de nuestra existencia. En ese sentido, es una sociedad donde por primera vez la información actúa sobre sí misma como principal forma de productividad, modificando por completo los entornos en los cuales operan las dinámicas del trabajo y por ende los procesos formativos y educativos que deben asimilar de algún modo ese cambio de escenario.

Al observar la globalidad del cambio y el consecuente incremento de la complejidad interna de los sistemas y su entorno, no resulta extraño entonces constatar el marcado sentimiento de perplejidad que se aprecia a la hora de plantear caminos de solución o alternativas para la adaptación de la universidad en la era de la información, a las nuevas necesidades que se generan y las competencias que se requerirán en el futuro próximo.

Francisco Inbernón, manifiesta esta sensación de la siguiente forma "El siglo XXI comienza ya más documentado que cualquiera de los anteriores, pero también es más incierto para una gran parte de la humanidad que el siglo XX. Aunque la incertidumbre forme parte intrínseca del tiempo en que nos ha tocado vivir, es parte del presente, hay sociedades y pueblos que no están preparados para afrontarla. No hay nada seguro bajo el sol: nos encontramos ante una nueva forma de ver 
el tiempo, el poder, el trabajo, la comunicación, la relación entre las personas, la información, las instituciones, la vejez, la solidaridad. De todo ello resulta, quizá, una cierta desorientación colectiva que se refleja en el pensamiento y en la acción educativa" (Imbernón, 2002:5-7).

$\mathrm{Al}$ parecer ello se incrementa permanentemente pues como se produce una aceleración del presente que impide un adecuado asentamiento, lo que a su vez resta valor referencial del pasado y hace que el ritmo de la vida se incremente, siempre al borde del abismo, siempre abocados al futuro (Gimeno, 2002).

En suma viviríamos un "traumático cambio de paradigma", pues las finalidades que se perseguían en la sociedad industrial y que las demás instituciones, incluida la educación, con sus fines y procedimientos incentivaban, se han modificado radicalmente en el marco de la sociedad de la información (Donoso, 1999). Además, como ello ha significado una acelerada mutación con rasgos ambivalentes que "incuba amplias perspectivas de progreso a la vez que entraña devastadoras secuelas sociales" (Perinat, 2004: 136).

En tanto que las operaciones básicas de la Universidad se encuentran directamente relacionadas con la producción, el almacenamiento, la transmisión y la crítica de la información, se sostiene con frecuencia que ante la inminente generalización de las nuevas tecnologías de la información y de la comunicación, estas cuatro funciones acabarán viéndose profundamente e inevitablemente afectadas (Ferraté, 1998).

Más allá de la sensación de perplejidad que se percibe en muchos de los actuales planteamientos sobre el tema, una constante se refiere a la ineludible necesidad e incluso obligatoriedad de la innovación continua, en un ambiente donde lo único seguro es el cambio permanente. Pero las adaptaciones no pueden ser al azar, deben ser capaces de servir como marcos adecuados para la acción de los sistemas; en palabras de Niklas Luhmann, permitir la reducción de la complejidad del entorno (Luhmann,1991; 1992; 1996, 1997). 
Los Sitios Web de las Universidades Privadas de Santiago en el marco de la Sociedad de la Información

De ese modo, en una sociedad compleja, los sistemas especializados en procesar conocimiento, producirlo y reproducirlo, se tornan cruciales no sólo para las personas que buscan nuevas oportunidades en futuros empleos que se espera exijan competencias que actualmente ellos no tienen, sino que para diversos subsistemas sociales que de una u otra forma buscan información especializada, innovación tecnológica, investigación aplicada, entre otros insumos.

En los países que conforman el G-7, ya se verifica no sólo el cambio en los procesos productivos sino una tendencia común hacia el aumento del peso relativo de la ocupación más claramente informacional (Flecha y Tortajada, 2002).

Algunas importantes mutaciones previstas por los especialistas debido al advenimiento de la sociedad de la información, aluden entre otras, al hecho de que el rápido desarrollo y producción de microtecnología supondrá una progresiva descentralización de estructuras a todos los niveles, se incrementará la especialización de las destrezas y requisitos laborales, así como la individualización de los intereses. La movilidad continuará aumentando, pero se elevará más la movilidad electrónica que la física, requiriéndose por tanto, que la educación se dote de nuevas estructuras, agentes y formas de gestión.

Para la universidades estas transformaciones resultan casi siempre problemáticas pues agudiza la tensión interna del sistema en la medida que este tipo de instituciones con tanta tradición no abandonan fácilmente sus disposiciones frente al entorno. Además se busca un conocimiento útil, gestado en la acción, orientado a resolver problemas, frente al contemplativo, en definitiva un nuevo modo de producir conocimiento de segunda generación para distinguirlo del modo tradicional, centrado en cada disciplina. Es un conocimiento que requiere un nuevo contexto de aplicación; es transdiciplinar, heterogéneo, móvil y no jerárquico (Perinat, 2004). 
Por supuesto no resulta fácil efectuar una síntesis del conjunto de cambios y efectos que han tenido lugar en las universidades. No obstante, el especialista español Miguel Ángel Zabalza, considera que se pueden resumir en seis grandes retos a los que la Universidad actual debe hacer frente en sus planes de acción:

1. Adaptarse a las actuales demandas del mundo del empleo, ofreciendo una formación que, sin renunciar a los contenidos básicos, capacite a sus estudiantes a un fácil acceso a la oferta laboral.

2. Situarse en un nuevo contexto de competitividad social donde va a primar la calidad y la capacidad para establecer planes e introducir ajustes.

3. Mejorar la Gestión, en un contexto de reducción de recursos públicos que exige la incorporación de nuevas fuentes de financiación y una mayor transparencia en la distribución de los mismos.

4. Incorporar las nuevas tecnologías, tanto en la gestión como en la docencia, y aprovechar su potencial para generar nuevas formas de relación interinstitucional y nuevos sistemas de formación (redes virtuales, enseñanza a distancia, etc.).

5. Constituirse como motor del desarrollo local tanto en lo cultural como en lo social y económico a través del establecimiento de redes de colaboración con empresas e instituciones.

Reubicarse en un nuevo escenario globalizado de formación y empleo y adaptar a él sus propias estrategias formativas: potenciando la interdisciplinaridad, el dominio de lenguas extranjeras, la movilidad de estudiantes y profesores, la investigación, los programas y sistemas de acreditación compartidos, etc. (Zabalza, 2002).

Estas expresiones resultan en muchos casos aún sólo deseos de buena voluntad, pues el proceso de ajuste recién parece estar comenzando. Aún no existe una visión panorámica que permita vislumbrar los grados, ritmos y dimensiones de las actividades universitarias que se están adaptando con mayor claridad a los cambios referidos. 
Los Sitios Web de las Universidades Privadas de Santiago en el marco de la Sociedad de la Información

\section{Universidad y Era de la Información en Latinoamérica y Chile}

Evidentemente el advenimiento de un nuevo orden socioeconómico a escala global no se vivencia del mismo modo en todos los contextos sociales, por lo tanto la relación entre universidad y era de la información estará ineludiblemente mediada por las particularidades en que dicho proceso ha ocurrido en América Latina y en cada sociedad nacional.

Hace más de diez años, en la primera Cumbre Iberoamericana de Rectores de Universidades Públicas efectuada en Santiago de Chile en 1999, se afirmaba que "En este proceso de globalización o mundialización, el punto de vista científico no nos debe conducir ni a una globofobia, ni a una globofilia, sino que desde el punto de vista universitario, científico y académico debemos profundizar sus consecuencias, profundizar su análisis y por supuesto, colaborar como universitarios en la solución, en la conducción, en todo aquello que se pueda ya que el objetivo de una Universidad debe ser una mejor calidad de vida en una sociedad más justa y solidaria" (Cantero,1999:50-51).

Como consecuencia particular, la universalidad también ha sido alcanzada por la globalización o, como prefieren llamar algunos, la internacionalización de la universidad, que para algunos autores conlleva beneficios importantes. Se considera por ejemplo que "varias ventajas representa esta progresiva internacionalización de las universidades. Mejora la disponibilidad de recursos, acelera la formación de académicos de buen nivel, eleva la calidad de la investigación, familiariza a las instituciones con los temas y desarrollos más de punta" (Riveros, 2002: 106).

El proceso que ya resulta altamente complejo dados los problemas sociales y económicos que arrastra la región, además de las particularidades culturales que se tornan altamente resistentes al cambio. Las dificultades no son completamente nuevas, pero sí su específica combinación (Sarukhan, 1998). Este contexto es importante y probablemente será cada vez más crucial en el 
futuro inmediato y en el largo plazo pues la sustentabilidad del modelo chileno de desarrollo no sólo depende del mantenimiento de las condiciones de una economía abierta a la globalización, un marco macroeconómico equilibrado, sino que además y como un proceso indispensable se requiere la transición tecnológica también de los recursos humanos y organizativos a un modelo informacional, basado en la capacidad de generación de conocimiento, recepción de transferencia tecnológica y formación de fuerza de trabajo de tipo informacional (Castells, 2005).

Existe preocupación en ciertos círculos universitarios en el sentido que las transformaciones globalizadoras, sobre todo de sentido altamente "economicista", signifiquen terminar con ciertos rasgos que se habían arraigado en las formas de vida en Latinoamérica. Como respuesta algunos consideran que la Universidad posee en ese sentido una gran responsabilidad, particularmente de crear una alternativa cultural frente al mercado, una especie de contracultura basada en el respeto a la identidad de nuestros pueblos (Rojas, 1999).

Más allá de las diferencias, teniendo en cuenta la inevitable velocidad de renovación del conocimiento, parece imponerse la idea de que la Universidad, tal cual fue concebida, estaría obsoleta o al menos se encontraría considerablemente desalineada con los tiempos.

Paralelamente, la centralidad que ha adquirido el mercado en la actualidad, puesto que anteriormente ocupó el sistema político a través de la acción del Estado en Latinoamérica y Chile, viene estableciendo un conjunto de nuevas exigencias relacionadas con el incremento de la competencia y ajustes a las reglas de orden económico y financiero a todas las instituciones sociales tradicionales y a los proveedores del sistema universitario, relacionadas con el incremento de la competencia, los ajustes a las reglas de orden económico y financiero, las tendencias a la virtualización de la enseñanza y la conformación de redes internacionales, entre otras (Rodríguez, 2003). 
Los Sitios Web de las Universidades Privadas de Santiago en el marco de la Sociedad de la Información

Por ejemplo, la utilización generalizada de estrategias de marketing por parte de las universidades tanto tradicionales como privadas, que permitan incrementar el acceso a lo que se ha denominado "mercado de la educación superior", la utilización frecuente de una nueva semántica que se refiere a los tradicionalmente estudiantes como "clientes" o la enseñanza superior como un "producto", que debe "competir" en un "mercado educativo", constituyen algunas nuevas tendencias que los planteles de educación superior no exhibían en el pasado reciente. Dichas condiciones del entorno han sido particularmente relevantes para las universidades privadas en Chile, las cuales se han estructurado en su mayoría durante los últimos 20 años.

Cabe señalar, a modo ilustrativo, que durante el año 2007, la inversión de las universidades chilenas por concepto de publicidad ascendió a \$ 19.374 millones, lo que representó un alza de un 26\% respecto del año anterior (Diario El Mercurio, 23 de nov. de 2007). Estos cuantiosos recursos no sólo tienen por objetivo atraer la atención de estudiantes y padres para que decidan su incorporación a determinada casa de estudios, sino que según lo declarado por las propias universidades, se relaciona con una estrategia que les permite dar a conocer las actividades que realizan y, para ponerlo en términos publicitarios, "construir marca" y diferenciarse de la competencia, especialmente para aquellas instituciones que poseen un débil reconocimiento en la opinión pública.

Al sector privado de la educación superior, que si bien ya posee actualmente 36 universidades instituidas desde comienzos de la década de los ochenta en Chile y evidentemente el fenómeno no puede considerarse nuevo, sin embargo, se le suele tratar como un ámbito homogéneo cuando en la realidad constituye un sector con distintos orígenes, misiones institucionales, tamaños, complejidad y formas de gobierno diversas (Fernández, 2009).

Para situar adecuadamente el problema, un aspecto que no es posible pasar por alto es el particular despliegue de la sociedad 
de la información en el continente y la acción de las universidades tanto del sector tradicional como privado. Dicha actividad adaptativa debe considerar las formas de diferenciación y complejidad social que se han desplegado en las sociedades latinoamericanas, las cuales presentan diferencias de fondo con el curso que ha seguido la modernidad europea.

Diversos intelectuales de los países de la región vienen subrayando este aspecto durante las últimas tres décadas (García Canclini, 1995; Lechner, 1997; Garretón, 2000 y Larraín, 2005, Rodríguez y Torres Nafarrate, 2008), enfatizando las diferencias culturales, socioeconómicas y políticas del universo latinoamericano, además de las respectivas particularidades nacionales que lo componen.

En la línea de la teoría de sistemas autorreferenciales, el sociólogo Aldo Mascareño (2000), formado en la línea sistémica de Luhmann, ha avanzado en la interpretación de las dinámicas propias de la diferenciación social en las sociedades latinoamericanas. Uno de sus principales postulados señala que las sociedades latinoamericanas no pueden ser consideradas completamente policéntricas como las europeas, donde cada sistema parcial goza de creciente autonomía y autopoiesis en la realización de sus operaciones y relaciones con el entorno.

En cambio el modo de diferenciación latinoamericana presentaría una dinámica "concéntrica", producto de que sistemas como la política y actualmente la economía, ejercen un "campo gravitacional" que concentra la comunicación social y que por tanto les permite situarse estructuralmente en una posición dominante y jerarquizada, bloqueando el despliegue completamente autónomo (policéntrico) de los demás sistemas parciales. En la región predominarían entonces formas de interdependencia que generan un orden jerarquizado y que ha tenido distintas manifestaciones históricas como el "centralismo estatal", que si bien se origina en el siglo XIX dominó gran parte del siglo XX a través de la determinación del proyecto industrializador, el estableci- 
Los Sitios Web de las Universidades Privadas de Santiago en el marco de la Sociedad de la Información

miento del Estado docente, la influencia en los medios masivos, el desarrollo científico, las manifestaciones artísticas, las redes de transporte, etc. La dependencia política y su capacidad desdiferenciadora, dejaría entonces espacio para niveles de autorreferencia básico en las demás esferas funcionales que se traducen en el predominio de esquemas de distinción difusos (fuzzy), producto de imposiciones externas de finalidades internas. Durante las últimas décadas el mercado adquiere mayor autonomía respecto de los objetivos políticos a la vez que incrementa notablemente su propia complejidad, afectando la capacidad de otros sistemas funcionales, que ante la pérdida de capacidad simbólica de la política, también elevan sus niveles de autorreferencialidad. Ello no implicaría la estructuración policéntrica de la sociedad puesto que ante la "retirada" del Estado, el mercado ocuparía a su vez una posición central (autarquía de mercado), que generaliza el dinero como medio de comunicación a todo el sistema social, tornando nuevamente difusas las distinciones de cada sistema funcional, favoreciendo la racionalidad monetaria en esferas no económicas (Mascareño, 2000).

A nuestro parecer, ejemplos de jerarquización sistémica centrada en el mercado no son difíciles de encontrar en el ámbito educativo en todos los niveles de enseñanza durante las últimas décadas. Las directrices con las cuales se planifica la acción universitaria, se ofertan nuevas carreras, se organizan mallas curriculares, se proyectan carreras, se adjudican presupuestos para actividades de investigación y extensión, se estructuran las plantas académicas, se enfrenta la promoción y la publicidad, se organizan los sitios y portales web institucionales, entre otras operaciones universitarias, vienen estando crecientemente afacetadas por las interacciones no-horizontales que el mercado establece con el resto de la sociedad y en particular con el sistema educativo, donde los códigos de selección comunicativa se han tornado difusos pues alternan discursos centrados tanto en la transformación de las personas como en la rentabilidad de la inversión en educación. 


\section{Educación Superior y difusión de las TIC}

Como han señalado diversos investigadores, los cambios asociados al advenimiento de la sociedad de la información generan sensibilidades, ritualidades, relaciones sociales, narrativas culturales e institucionalidades distintivas donde la tradición de los grandes "sólidos modernos" se trasmuta produciendo una novedosa relación adaptativa frente al complejo entorno de este nuevo escenario social. Dicho cambio no deviene por mera presencia en la construcción del conocimiento, debido a que la conectividad en sí misma no asegura que la comunicación sea provechosa ni resuelva automáticamente la interactividad didáctica en el campo del saber (San Martín, 2003).

Desde este marco, las respuestas institucionales retratan experiencias de distinto tipo, tal como han enfatizado las contribuciones de Salinas (1997, 1998 y 2000). Entre otras, se pueden señalar: Programas de innovación docente en las universidades, sobre todo, relacionados con la incorporación de las TIC en los procesos de enseñanza aprendizaje, modificación de las estructuras universitarias, en cuanto que comienzan a ser consideradas estas tecnologías en el organigrama y en los órganos de gestión de las universidades, y experiencias innovadoras de todo tipo relacionadas con la explotación de las posibilidades comunicativas de las TIC en la docencia universitaria.

Otro factor que prevalece es la mayor colaboración internacional en el ámbito universitario ligado a los avances en las tecnologías de la información y la comunicación, lo cual modifica las prácticas, orientaciones y estrategias académicas utilizadas habitualmente hasta ahora.

Una experiencia pionera en este ámbito la constituye la primera "ciberuniversidad", que ha visto otras experiencias similares del dos mil hacia acá. La Universitat Oberta de Catalunya, que basó su modelo educativo no presencial en el campus virtual, lo definió como el conjunto de múltiples funcionalidades que ha- 
Los Sitios Web de las Universidades Privadas de Santiago en el marco de la Sociedad de la Información

cen posible la interacción entre los colectivos que componen la Universidad (estudiantes, profesores y personal de gestión) sin necesidad de coincidir ni en el tiempo ni en el espacio (Ferraté, 1998:186).

Estos énfasis no son recientes, ya hace más de una década, en el artículo 12 de la Declaración Mundial sobre la Educación superior en el siglo XXI: Visión y acción (Conferencia Mundial sobre la Educación Superior, 1998), bajo el título de El potencial y los desafíos de la tecnología, los especialistas insisten sobre la necesidad de nuevas iniciativas en la explotación de las posibilidades de las TIC en los procesos de enseñanza-aprendizaje universitarios (Moran y Myringer, 1999).

En suma, como la evidencia empírica indica, las instituciones de educación superior han experimentado un cambio de importancia, desplazando de manera parcial en ciertos casos y de manera más amplia en otros, los procesos de formación desde modalidades convencionales a entornos que involucran medios de enseñanza asistidos por computación, la utilización de modelos virtuales, bases de datos, multimedia, Internet, etc. En ese proceso las universidades han procesado las demandas sociales para que los estudiantes reciban las competencias para el aprendizaje continuo y simultáneamente potenciar las oportunidades para acceder a nuevos mercados, generando un conjunto de presiones hacia el interior del sistema educacional que debe ajustar las prácticas de enseñanza y aprendizaje y la organización de los planes de estudio.

Se ha escrito mucho sobre las posibilidades y limitaciones de las TIC en los procesos de enseñanza en distintos niveles. Un resumen panorámico de las principales ventajas y desventajas examinadas por Marqués (2000), referidas a un conjunto de evidencias empíricas e investigaciones de diverso alcance, pueden observarse en el siguiente cuadro: 
Ventajas e inconvenientes de las TIC

\begin{tabular}{|c|c|}
\hline VENTAJAS & INCONVENIENTES \\
\hline \multicolumn{2}{|c|}{ DESDE LA PERSPECTIVA DE LOS CENTROS } \\
\hline $\begin{array}{l}\text { - Los sistemas de teleformación } \\
\text { pueden abaratar los costes de } \\
\text { formación. } \\
\text { - Los sistemas de teleformación } \\
\text { permiten acercar la enseñanza a más } \\
\text { personas. } \\
\text { - Mejora de la administración y } \\
\text { gestión de los centros. } \\
\text { - Mejora de la eficacia educativa. } \\
\text { - Nuevos canales de comunicación } \\
\text { con las familias y con la comunidad } \\
\text { local. } \\
\text { - Comunicación más directa con la } \\
\text { Administración Educativa. } \\
\text { - Recursos compartidos. } \\
\text { - Proyección de los centros. }\end{array}$ & $\begin{array}{l}\text { - Costes de formación del } \\
\text { profesorado. } \\
\text { - Control de calidad insuficiente de } \\
\text { los entornos de teleformación. } \\
\text { - Necesidad de crear un } \\
\text { departamento de Tecnología } \\
\text { Educativa. } \\
\text { - Exigencia de un buen sistema de } \\
\text { mantenimiento de los ordenadores. } \\
\text { - Fuertes Inversiones en Hardware y } \\
\text { Software. }\end{array}$ \\
\hline
\end{tabular}

FUENTE: Marqués, 2000.

Los estudios muestran que cuando los entornos tecnológicos de última generación se aplican a la enseñanza superior, surgen los espacios virtuales, los cuales se constituyen como una posibilidad de enseñanza de nivel universitario accesible desde cualquier lugar y a cualquier hora a partir de la conexión a una red telemática. El uso de la expresión campus virtual, no está de más, ya que sugiere que una vez hecha la conexión a la red, cualquier persona tiene acceso a las posibilidades de formación como también acceso a toda clase de servicios académicos y no académicos.

Otras experiencias en ese sentido son las actividades denominadas Open Course Ware (OCW), que constituyen archivos de información que contienen los materiales de clase con códigos abiertos en la red. Estas experiencias pioneras fueron efectuadas por primera vez por el Instituto Tecnológico de Massachusetts (MIT), hacia el año 2001, sumándose posteriormente distintas universidades a nivel mundial. En definitiva se trata no de posibilitar titulaciones on-line, sino que potenciar la sociedad del 
Los Sitios Web de las Universidades Privadas de Santiago en el marco de la Sociedad de la Información

conocimiento y potenciar vinculaciones posteriores que amplifiquen aplicaciones, redes o posibles proyectos mediante la difusión del material que se discute al interior de los centros de pensamiento y enseñanza.

Por otra parte la sociedad del conocimiento y la información exige al desarrollo económico productivo una variedad de instrumentos tecnológicos que apoyen no sólo a la conformación de los recursos simbólicos y sociales en sus campos mediatos de acción, sino que también orienten a las empresas y científicos, hacia la cooperación de una economía que sea capaz de sustentar tanto el crecimiento y desarrollo a partir de nuevos materiales, estructuras y oportunidades.

Los puntos de inflexión frente a este proyecto derivan del aprendizaje de las lecciones de la denominada "nueva economía", que ha olvidado en gran medida la importancia de anteponer a sus expectativas comerciales e inversoras, una base más amplia y equilibrada que tomara como punto de partida la educación y la extensión de sus posibilidades al conjunto de la población en el contexto de un cambio cultural. Desde este ámbito la ciencia y las universidades deberían tomar en consideración al mercado pero sin la necesidad de supeditarse a él (Pedreño, 2001).

Nos encontramos hoy en una época donde las universidades y los organismos gubernamentales se ven en la necesidad de reinventar nuevas relaciones entre el quehacer científico y las empresas, incorporando en las primeras el advenimiento de la cultura del emprendimiento y la innovación; en la medida que la evolución clásica del componente industrial de las naciones, necesita una mano de obra preparada para resolver los desafíos tecnológicos propuestos por este nuevo tipo de economía. Las bases conceptuales de esta nueva misión que se le impone a la universidad tiene su asidero principal por un lado, en el desarrollo de la enseñanza de las profesiones intelectuales, para tener una mano de obra calificada acorde a los imperativos sistémicos impuestos, y por otro, en el desarrollo de la investigación cientí- 
fica y preparación de los futuros investigadores, a razón de hacer frente a los desafíos de naturaleza cultural, científica y profesional (Bueno, 2007).

Explícitamente, lo que se ha denominado "la tercera misión de la universidad", se juega en el enlace entre su función emprendedora y de innovación, tornándose en motor de creación y transferencia de todo el conocimiento diseminado en su entorno (Etzkowitz, 2000; Schulte 2004). Expresado de otro modo, la educación superior debe dirigir el proceso de transferencia del conocimiento orientado a la generación de innovaciones, formando una política de la cultura científica acorde al ámbito de la investigación capaz de transferir conocimiento y formar al mismo tiempo a los asesores y gestores científico-técnicos (Bueno, 2007).

No obstante lo anterior, la integración efectiva de las tecnologías de la comunicación y la información a los procesos principales de la operatoria universitaria aún no se constata con precisión, particularmente en la región latinoamericana. En cambio se aprecia considerable presencia de las nuevas tecnologías en la presentación pública de las universidades mediante sus respectivas páginas web. Este fenómeno ya se observa desde mediados de los años noventa en Chile y ha recibido escasa atención por parte de los especialitas. En tanto las universidades tradicionales y privadas están efectuando un uso intensivo de esta plataforma para difundir su imagen ante la opinión pública y servir como portal para procesos administrativos y mecanismo de comunicación e interacción entre académicos y estudiantes. Adicionalmente, constituyen una forma particularmente relevante para dar a conocer las actividades efectuadas por las diversas casas de estudio, dar a conocer y resaltar los resultados que alcanzan en procesos de acreditación institucional y de carreras como mecanismo de certificación de calidad ante determinados públicos estratégicos.

Un interesante estudio efectuado sobre una muestra de 150 sitios web de universidades norteamericanas, divididas entre 
Los Sitios Web de las Universidades Privadas de Santiago en el marco de la Sociedad de la Información

acreditadas y no acreditadas, mostró mediante un análisis cuantitativo de diferencias que las imágenes utilizadas, los mensajes de marketing y los temas de comercialización, no están siendo bien aprovechados como elemento de promoción y ventaja comparativa por las universidades acreditadas a la hora de poner énfasis en el resultado alcanzado, los profesores y la calidad de la educación que imparten (Adams y Eveland, 2007).

Las formas en que estos recursos tecnológicos se utilizan para relacionarse con el medio y dar cuenta de la propia actividad institucional, la medida en que reflejan las misiones y visiones prevalecientes en cada casa de estudios, la amplitud y profundidad de procesos pedagógicos y administrativos asociados, el grado de penetración en los diversos actores relevantes como profesores, alumnos y público en general, o los impactos efectivos que están generando, aún se desconocen en nuestro país.

Este trabajo pretende un primer acercamiento descriptivo de la utilización de los sitios web como presentación pública de las universidades del sector privado de la Región Metropolitana, de modo que puedan desprenderse dimensiones de discusión respecto del alcance que posee este recurso tecnológico en el contexto del desarrollo de la sociedad de la información en el país.

\section{Descripción de los sitios WEB de las Universidades Privadas de la Región Metropolitana de Santiago}

Los sitios web institucionales constituyen en la actualidad en Chile uno de los principales medios por los cuales las universidades dan a conocer información de carácter oficial a diversos públicos internos y externos, lo cual ha seguido una tendencia impuesta por las principales universidades a nivel internacional. Dicha información, que se ha tornado cada vez más pormenorizada y que evoluciona con gran rapidez, permite obtener una caracterización preliminar de algunos rasgos generales de las casas de estudio de nivel superior, a partir de un conjunto de datos típicos 
que se incorporan de manera frecuente en los sitios oficiales.

El acceso a información tal como cuentas anuales, documentos referidos a auto-evaluaciones institucionales, entre otros, son de manejo restringido y confidencial. Por otra parte las cuentas anuales constituyen documentos que no son realizados por todas las universidades privadas, y los publicados no cuentan con la actualización correspondiente para una adecuada descripción.

De ese modo los sitios web de los planteles de educación superior constituyen la opción más directa para acceder a las distinciones comunicativas y declaraciones de las universidades privadas, a la vez que ofrecen un conjunto considerable de información, oficial, actualizada y comparable.

La información que se presenta en este artículo fue recopilada entre los meses de octubre y noviembre del año 2008. Para la organización general de los datos se elaboró una matriz general que reúne y ordena de manera resumida según las principales dimensiones consideradas los datos contenidos en los 18 sitios web analizados de manera general. Adicionalmente, en la sección se presenta una descripción más específica de otros seis sitios seleccionados al azar, lo que reúne un total de 24 sitios considerados para la caracterización de los portales web de las universidades privadas de la Región Metropolitana.

Las casas de estudio que incorpora la matriz, son todas las universidades privadas de la Región Metropolitana que poseían al momento de efectuarse la recopilación sitios web activos. La descripción de los web-site de la matriz incorpora 8 dimensiones de caracterización, a saber:

1) Información referida a su misión, visión y objetivos estratégicos.

2) Dimensiones resaltadas en su publicidad.

3) Elementos de presentación o mapa del sitio, donde se presenta cada una de las instancias que tiene la universidad.

4) Áreas consideradas en su website las cuales comprenden 
Los Sitios Web de las Universidades Privadas de Santiago en el marco de la Sociedad de la Información

número de carreras impartidas, cantidad de posgrados, magíster, diplomados, centros de estudio, facultades y acceso a publicaciones de índole virtual.

5) Disponibilidad en su website de intranet o algún elemento de comunicación administrativo docente de carácter virtual.

6) Información sobre el proceso de acreditación de la casa de estudio.

7) Organización, estética y desarrollo de su portal web y los recursos técnicos asociados a éstos, ya sea Facebook, flicker, modyo o alguna forma de comunidad virtual.

8) Presencia de plataforma e-learning, en el caso que la universidad ofrezca cursos a distancia o en formato virtual, con los respectivos cursos que se imparten.

\subsection{Misión y Visión}

En esta dimensión es posible constatar un conjunto de similitudes pero también un conjunto de diferencias. En todos los casos de sitios web observados encontramos de manera explícita la presencia de una descripción resumida de la visión y misión con la cual se compromete cada universidad. Normalmente dicha declaración de principios se encuentra en un lugar destacado y casi siempre en una "pestaña" o espacio del sitio dedicado a los aspectos denominados "Institucionales" o también llamado "Nuestra universidad", "Quienes somos" o simplemente "universidad", como los principales apartados en los cuales se presentan estas declaraciones generales de propósito.

Un primer aspecto general observado es la alta coincidencia que presentan algunos valores típicos comunes detectados en la mayoría de las misiones o visiones. Así por ejemplo, el énfasis en la formación de profesionales, competentes, innovadores, productivos y creativos. De manera frecuente se aprecian valores generales asociados a una formación integral, como la responsabilidad, independencia, el pluralismo, la autonomía, el espíritu de superación y la honestidad. A la vez, una gran mayoría de las universidades considera la necesidad de que sus egresados sean 
útiles a la sociedad, con espíritu de servicio, así como la contribución al desarrollo social y cultural del país.

Sin embargo, también se observan ciertas diferencias en los valores, que normalmente aparecen asociadas con mayor claridad, cuando la universidad declara de modo explicito, su adscripción a una determinada tradición, doctrina o visión de mundo religiosa o ideológica. Nueve de los dieciocho casos analizados declaran de manera nítida su adhesión doctrinaria en sus declaraciones de visión y misión.

En estos casos se detectan orientaciones axiológicas más específicas tales como "valores de la cultura cristiano-occidental" (Universidad Finis Terrae), "concepción cristiana del ser humano y el mundo" (Universidad Alberto Hurtado), "verdad cristiana" y "amor al trabajo", "Inspirándose en el espíritu del Opus Dei" (Universidad de los Andes), "valores que se desprenden de las sagradas escrituras", "valores de educación adventista" (Universidad Adventista de Chile), "emprendimiento", "virtudes morales" (Universidad Santo Tomás), "espíritu emprendedor" (Universidad de Artes, Ciencias y Comunicación), "sistema educativo salesiano" (Universidad Católica Silva Henríquez), "Espíritu de servicio, el orden y la ética profesional" (Universidad Bernardo O'Higgins), "cultura de la universidad-empresa", "contribuir de crítica", "integración social" (Universidad Academia de Humanismo Cristiano), "reflexiva y crítica” (Universidad ARCIS).

No deja de llamar la atención que una orientación más clásica o que enfatiza el desarrollo del conocimiento, la investigación y la producción y difusión del saber se encuentra explícitamente declarado sólo en siete de las dieciocho portales web considerados.

Por otra parte, desde objetivos centrados en la propia posición de la institución, cuatro de las diecinueve universidades, comprometen en su visión o misión el logro de una "posición de prestigio", constituirse en "una universidad de excelencia" o entre "las universidades privadas más relevantes del país". 
Los Sitios Web de las Universidades Privadas de Santiago en el marco de la Sociedad de la Información

Resulta interesante que sólo un caso nombra de manera explicita la globalización como un aspecto relevante en su declaración. No se registran de manera directa alusiones a la sociedad de la información o a las nuevas tecnologías de la información.

\subsection{Dimensiones resaltadas}

Un aspecto relevante de analizar lo constituye el énfasis especial que colocan las organizaciones universitarias en sus respectivos portales web. Normalmente esta dimensión parece enfocarse en los potenciales estudiantes, adquiriendo rasgos de índole publicitaria, teniendo en cuenta la inclusión de ideas fuerza destacadas, la frecuente utilización de frases cortas y la presencia de diversas formas para resaltar la información (colores vivos, tamaño de las letras, ubicación, etc).

El aspecto más destacado resulta ser la información referida a la acreditación, la cual figura de manera remarcada en nueve de los diecinueve casos; en la gran mayoría de ellos se incluye además el período obtenido como consecuencia del proceso.

Entre las nociones que más se repiten, también se encuentran alusiones a la excelencia y la calidad académica de los profesores (en cinco de dieciocho casos), donde se indican los porcentajes de académicos con postgrado o afirmaciones similares.

Aspectos relativos al tamaño de la institución, mediante información sobre el número de alumnos matriculados o egresados a modo de promoción, se subraya en cuatro de los sitios considerados, mientras que alusiones a la calidad y cantidad de infraestructura y equipamiento disponible, se indica en dos casos, al igual que aquellos sitios donde se resaltan los años de experiencia en el rubro, el porcentaje de egresados que se encuentran trabajando y el nivel académico de los estudiantes (puntaje PSU o notas de enseñanza media, promedio).

Otros aspectos que se recalcan también son aquellos alusivos a la pertenencia a una red internacional de educación, los niveles 
de satisfacción de los alumnos, las posibilidades de dobles titulaciones, el intercambio entre la universidad y la empresa, el número de proyectos artísticos o académicos realizados como libros o investigaciones.

\subsection{Elementos de presentación o mapa del sitio}

La observación de este aspecto indica una gran similitud en los principales elementos que organizan la información de los respectivos sitios web de las universidades consideradas en esta descripción. Efectivamente, la gran mayoría cuenta con una arquitectura donde, con escasas excepciones, se encuentran apartados referidos a aspectos generales de la universidad, mensaje de rectoría, información sobre las principales autoridades, historia, misión y visión, fotos, videos o mapas descriptivos de las casas centrales y sedes, espacios o pestañas para postulación y admisión, servicios generales de alumnos, ex-alumnos, servicios de biblioteca, noticias, apartados para sedes, facultades, escuelas y carreras, extensión y secciones especiales para alumnos y profesores.

A su vez, la gran mayoría de los sitios web presentan secciones especiales para lo que denominan "Postgrados", "Formación continua" o "Cursos de capacitación". Aspectos más específicos relacionados con un conjunto de factores manifiestan mayor diversidad. Así por ejemplo, las universidades que establecen secciones especiales para informar las actividades de investigación que realizan alcanzan a diez de las dieciocho. En tanto las que dedican un espacio virtual para otorgar información y difusión específica a sus publicaciones son sólo cuatro.

Cinco universidades generan en su sitio un apartado para promover los convenios internacionales y las posibilidades de intercambio con universidades y centros de estudio del extranjero.

Dos de los portales considerados incorporan en los elementos de presentación apartados referidos específicamente a información referida a procesos de acreditación. 
Los Sitios Web de las Universidades Privadas de Santiago en el marco de la Sociedad de la Información

\section{4 Áreas consideradas en su website}

Todos los sitios web considerados registran información específica sobre sus programas o carreras, cursos de postgrados, diplomados, postítulos, seminarios, etc. La principal diferencia se encuentra en la forma en que se organiza la información. Algunos incorporan datos de manera más pormenorizada, diferenciando estas áreas, mientras que otros agrupan sus registros según las facultades que posean. Cinco de las dieciocho páginas web presentan información sobre centros, observatorios o institutos de investigación o estudio, en los cuales se indican los proyectos y actividades específicas que realizan.

\subsection{Disponibilidad en su website de intranet o algún elemento de comunicación administrativo docente de carácter virtual.}

Todas las páginas incorporan un sistema de intranet o servicio de administración docente donde los alumnos y profesores pueden acceder mediante claves para efectuar una variedad de trámites, o actividades administrativas tales como toma de ramos, incorporación de calificaciones, actualizar la agenda de asignaturas, o de índole comunicativa entre alumnos y profesores.

\subsection{Información sobre el proceso de acreditación de la casa de estudio}

Trece de los diecinueve sitios contienen información adicional sobre el proceso de acreditación. Habitualmente ello incluye la historia del proceso o cuando es el caso la etapa específica en la que se encuentra, así como la documentación que respalda dicha situación y el período obtenido. También en algunos casos se agrega el informe de acreditación emanado por la CNA entre otros documentos de dicho organismo. 


\subsection{Organización, estética y desarrollo de su portal web y los recursos técnicos asociados}

La tendencia internacional que señala la importancia que están adquiriendo los sitios virtuales como plataforma de presentación, difusión, interacción y desarrollo de las universidades a nivel mundial, queda reflejado en la permanente preocupación que las organizaciones universitarias tienen para actualizar, ampliar la información y mejorar los servicios que integran. Dicha tendencia también tiende a manifestarse en los casos analizados. Efectivamente catorce de los dieciocho sitios presentan un desarrollo apreciable de recursos estéticos, variedad de aplicaciones y organización de la información, lo que muestra una especial atención a este tipo de recursos comunicacionales.

Llama la atención que cuatro de los sitios universitarios incluyen recursos de la denominada "web 2.0", es decir, el conjunto de modalidades de segunda generación en la historia de la web, que incluye todas aquellas formas basadas en comunidades de usuarios y un conjunto diverso de servicios tales como las redes sociales, los "blogs", "wikis", facebook, etc. Estos recursos se destacan como plus tanto para la difusión que puedan efectuar los académicos como de las comunidades que puedan articular los propios alumnos. Sin embargo, más que las restricciones técnicas que puedan existir para su mayor implementación, implican un menor grado de control en los contenidos de la información por parte de cada universidad.

\subsection{Presencia de plataforma e-learning}

Sólo dos sitios de los dieciocho caracterizados, incluye plataforma para cursos e-learnig, con una cierta variedad de programas a distancia mediante la utilización de la plataforma tecnológica ofrecida por la propia universidad.

La caracterización general de los sitios web de las dieciocho universidades privadas de la Región Metropolitana, excluyendo los casos seleccionados para la investigación que son analizados 
Los Sitios Web de las Universidades Privadas de Santiago en el marco de la Sociedad de la Información

en forma independiente en la siguiente sección, muestran un evidente interés de las casas de estudios por efectuar un conjunto de acciones mediante este recurso tecnológico que de manera creciente ha sido incorporado a nivel internacional.

\section{Profundización de Seis Páginas Web de Universidades Privadas}

En la presente sección se realiza una descripción más pormenorizada de los sitios web de las seis Universidades Privadas que han sido seleccionadas al azar. Como una forma de salvaguardar la confidencialidad se utilizarán letras para referirse a cada universidad.

Se han seleccionado cuatro dimensiones principales para efectuar la descripción de los sitios web respectivos. Estos aspectos son: Misión y visión publicitada en su website, Estructura de la página web y la Publicidad y propaganda de website.

\subsection{Universidad A}

Esta Universidad se encuentra acreditada desde noviembre del 2006 hasta noviembre del 2011, fue fundada en 1990 y cuenta con dos sedes, una en Santiago y otra en Concepción, con un total de 8.069 alumnos.

\subsubsection{Misión y visión}

Según el portal, la Universidad A tiene por misión contribuir a la formación de profesionales de excelencia y a la generación de investigación y extensión, fomentando el emprendimiento, el amor al trabajo bien hecho, el actuar ético y la responsabilidad pública. Su visión es ser reconocida como una institución de educación superior de alto prestigio, líder en la innovación académica, comprometida en la formación de profesionales íntegros y en el fomento de la iniciativa y del emprendimiento al servicio de la sociedad.

Sus principios y valores aseguran: 1) Compromiso con el desarrollo de una sociedad de personas libres. 2) Adhesión a los 
valores del humanismo cristiano. 3) Libertad de pensamiento, diversidad y su libre expresión. 4) Excelencia Académica. 5) La Tolerancia y No Discriminación.

El portal afirma que los estudiantes deberían escoger formarse en esta universidad porque: 1) Cuenta con un cuerpo docente de reconocido prestigio académico y profesional. 2) Posee programas que enfatizan lo integral y lo estratégico. 3) Utiliza modernos métodos y técnicas de enseñanza. 4) Es reconocida como una de las cuatro mejores Universidades privadas de Chile. 5) Cuanta con sedes en las dos principales ciudades del país. 6) Tiene un estrecho contacto con el mundo empresarial. 7) Cuenta con un espíritu de liderazgo. 8) Posee intercambio académico con importantes universidades extranjeras.

\subsubsection{Estructura de la página web}

En términos generales el grado de información de esta Universidad otorgada en su portal es amplio, diverso y detallado. En la parte superior del portal nos encontramos con un motor de búsqueda que permite ingresar mediante algunas palabras clave a la información que está contenida en el sitio. Paralelamente posee un vínculo de acceso rápido a todos los tópicos importantes para la universidad, a saber: registro académico en línea, centro de emprendimiento e innovación, MBA, el centro de políticas públicas, mediática, postgrados, facultades de las carreras, extensión y capacitación, guía de expertos, biblioteca, CFE, PAEX, CIEN, renovación telefónica de préstamos, y admisión.

En la admisión correspondiente al 2009, se encuentran señaladas todas las carreras que imparte la universidad en pregrado tanto en su sede de Santiago como Concepción. En este lugar, se puede acceder a los requisitos de postulación, solicitar información on-line sobre la universidad, informarse respecto de todas becas académicas por carreras, y documentarse sobre las visitas que pueden efectuar los terceros y cuartos medios para conocer a la universidad. 
Los Sitios Web de las Universidades Privadas de Santiago en el marco de la Sociedad de la Información

El portal cuenta con un canal especial denominado "Modyo" para acceder a foros internos de la institución e integrar una red interactiva de comunidad virtual.

Conforme a las carreras de pregrado, éstas se pueden seleccionar con un link para cada una de las facultades a modo de obtener una descripción general de cada carrera en cuestión. Específicamente, se pueden realizar consultas on-line, informarse sobre el perfil profesional de cada una de las carreras, su malla curricular, consultar el staff de profesores, acceder a todas las publicaciones que ha realizado cada una de las escuelas, sumado a la documentación y reglamentación interna de la universidad.

En esta misma línea también es posible documentarse acerca de cuáles son las autoridades de las facultades, su historia y los intercambios al extranjero. También se promocionan las carreras de posgrado que se imparten tanto para Santiago como en Concepción.

Existe un vínculo de información para alumnos que cuenta con: calendario académico, el registro académico, asuntos estudiantiles, servicios on line, biblioteca, y un vínculo especial para su sede en Concepción. Dentro de los servicios ofrecidos por el portal, éste cuenta con un apartado especial de: on-line "miUniversidad", webmail, guía de expertos y cursos en la web para alumnos.

El portal cuenta con un Centro de Desarrollo de la Docencia para atender a las demandas que hoy enfrenta el sistema universitario, contiene además cuáles son los equipos de trabajo, los cursos, documentos, reforma curricular y metodología para enfrentar los actuales desafíos de la sociedad chilena. Paralelamente en este mismo espacio virtual, es posible encontrar el proyecto de desarrollo docente, sitios de interés, fondos concursables con sus respectivas bases y formularios, juntamente a los fallos de adjudicación de estos fondos.

Existe una red de ex alumnos donde éstos pueden ir actualizando sus datos como también una bolsa de empleo para los mismos. 
El website contiene un banner a través del cual es posible informarse sobre las relaciones internacionales, los convenios que tiene la universidad con diversos centros y universidades en el extranjero, consideraciones y procedimientos para acceder a la doble titulación, intercambio estudiantil, formularios de convalidación, etc.

Paralelamente el portal cuenta con una biblioteca virtual en la cual es posible ubicar boletines bibliográficos, bases de datos, ediciones de la universidad $\mathrm{A}$, catálogos y colecciones on-line.

\subsubsection{Publicidad y propaganda en el sitio web}

$\mathrm{Al}$ ingresar al portal de Internet de la universidad $\mathrm{A}$, lo primero que se encuentra es una animación flash que señala que esta universidad es la número uno en emprendimiento en Latinoamérica según el ranking MBA de América Económica 2008. Acto seguido se presenta como una universidad de excelencia entre todas las universidades privadas del país y la mejor acreditada según la Comisión Nacional de Acreditación, en la medida que ésta obtuvo cinco años de acreditación institucional en cuatro áreas.

El website señala que para entrar a estudiar a esta universidad en las carreras que poseen mayor demanda es necesario haber obtenido en promedio 680 puntos rendidos en la prueba de selección universitaria.

De otra parte, la Universidad A, asegura haber sido la institución con mayor crecimiento en AFI 2008, según las fuentes del Ministerio de Educación, toda vez que obtuvo un crecimiento de $42,02 \%$ situándose muy por sobre la segunda Universidad que lo hizo en un $23,29 \%$. La Universidad A publicita en su sitio de Internet que lidera el ranking de las universidades privadas que se adjudicaron los concursos Fondecyt del año 2008, con cuatro proyectos los cuales fueron aprobados con 95.521 .000 de pesos para el primer año de ejecución.

Entre las Palabras claves de su publicidad se encuentran los siguientes conceptos: La mejor universidad privada del país según 
Los Sitios Web de las Universidades Privadas de Santiago en el marco de la Sociedad de la Información

documentación estadística/Comprometida con el emprendimiento y la excelencia/ La mejor Universidad acreditada del país.

\subsection{Universidad B.}

La Universidad B se encuentra acreditada desde diciembre del 2005 hasta diciembre del 2009, fue fundada en 1988 y cuenta un total de 15.956 alumnos.

\subsubsection{Misión y visión}

Según el portal de la Universidad B, esta casa de estudios se encuentra orientada a la docencia, abierta e independiente, comprometida con la formación de profesionales cultos y emprendedores, como también con el desarrollo, la preservación y divulgación del saber superior, lo cual está al beneficio de las personas y a la contribución del progreso de la nación.

Sus vectores de desarrollo estratégico están encaminados a: 1) Mantener a la universidad como una institución con innovación y liderazgo en el ámbito nacional en el proceso de formación de profesionales. 2) Incrementar su contribución al entorno cultural educacional, social y económico. 3) Continuar su vinculación con el entorno internacional de educación superior y profesional. 4) Asegurar la efectividad y eficiencia de las gestiones de sus RRHH, materiales y financieras. 5) Continuar su proceso de aseguramiento de la calidad.

El portal web sostiene que sus valores y principios son: 1) Libertad académica. 2) Un equilibrio entre la formación científica y tecnológica y un profundo humanismo. 3) Espíritu de emprendimiento. 4) Autoevaluación permanente. 5) Compromiso con la excelencia y la calidad.

\subsubsection{Estructura de la página web}

El website en su portal de inicio otorga escasa información sobre el desarrollo de la institución y opta por una estrategia basada en imágenes de su cuerpo docente y estudiantado a través de animaciones flash. 
El acceso a la información en el sitio se encuentra supeditada a links dentro de los cuales destacan los siguientes enlaces: universidad, admisión, estudiantes, académicos, pregrado, postgrado e intercambio.

En la parte superior de la página es posible acceder al portal estudiantil, intranet, correo de la universidad y al portal docente. Al interior del link admisión 2009, se encuentra la posibilidad de realizar una postulación on-line, documentarse sobre las facultades y carreras que imparte la universidad, sus programas especiales, las matrículas y aranceles, becas y crédito, los logros que ha tenido la universidad, sus convenios y sedes.

$\mathrm{Al}$ interior de cada link de carrera se encuentra la posibilidad de documentarse sobre la malla curricular, el perfil profesional del egresado, los profesores, las formas de postulación y la simulación de sus créditos. Cabe destacar que al interior de cada una de estas sub-páginas el portal privilegia la estética por sobre el contenido, ubicando fotografías de sus alumnos acompañadas de "frases célebres" y fichas técnicas de las carreras.

\subsubsection{Publicidad y propaganda en el sitio web}

$\mathrm{Al}$ introducirse en el portal se publicita a través de una cronología los logros obtenidos por la universidad, se señala que es la primera universidad privada que funda el área de la Ciencia y la Tecnología mientras que las restantes universidades privadas incursionaban en carreras de baja inversión.

El website plantea que fue la primera universidad privada en crear las carreras de Agronomía en Ingeniería Forestal, Medicina Veterinaria, Odontología y Medicina; al mismo tiempo que fue la primera universidad que fundó la primera Clínica Odontológica de una universidad privada y que se consolidó en el año 2001 en el primer lugar dentro de las privadas en AFI (aporte fiscal indirecto). El portal pone énfasis también en que ésta universidad fue la primera universidad privada que creó el conservatorio de música y que consolidó actividades científico-tecnológicas. 
Los Sitios Web de las Universidades Privadas de Santiago en el marco de la Sociedad de la Información

Por otra parte, en el año 2005 destaca que fue Acreditada por la Comisión Nacional de Pregrado, y que en el 2006, fue la primera universidad de América Latina en alcanzar el estatus de candidata a Acreditación Internacional por Middie States Commission on Higher Education. Señala que en el año 2007, la Escuela de Medicina logra la acreditación ante la CNAP y Mercosur, convirtiéndose en la primera escuela en su área, de una privada en acreditarse.

Entre las palabras claves utilizadas en su publicidad se encuentran las siguientes: La primera universidad privada pionera en varios ámbitos de desarrollo y acreditada ante la CNAP.

\subsection{Universidad C}

La Universidad C se encuentra acreditada desde diciembre del 2005 hasta diciembre del 2008, fue fundada en 1982 y cuenta con un total de 6.116 alumnos.

\subsubsection{Misión y visión}

Según el portal de la Universidad C, su misión es servir al país desde el quehacer universitario comprometiéndose con la excelencia integral, la generación de redes con la sociedad y con la sustentabilidad. Siendo los valores que la inspiran la excelencia, integridad, libertad y tolerancia, compromiso con el país y participación.

La página web señala que esta universidad, junto con otras dos instituciones son las universidades privadas más antiguas de Chile, y que se encuentra acreditada institucionalmente desde el año 2005.

El portal plantea que una de las principales características de esta universidad es ser una corporación de derecho privado, sin fines de lucro, cuya administración y desarrollo recae en sus propios docentes, convirtiéndola en un caso único en Chile.

Se destaca el hecho que cuenta con una infraestructura y equipamiento de primer nivel y en constante renovación. 
La Universidad C plantea en su portal que busca formar profesionales integrales, emprendedores e innovadores con un alto sentido social.

\subsubsection{Estructura de la página web}

En la parte superior del portal se puede acceder a los canales de redes interactivas Facebook y "Modyo" (comunidad virtual), al mismo tiempo que a un motor de búsqueda para ubicar algún ámbito específico dentro del portal.

La página posee la opción de conocer a la universidad, sus facultades y carreras, establece enlaces directos a las áreas de posgrados, seminarios, cursos, investigaciones, análisis y estudios, asuntos internacionales y publicaciones.

En el área de investigación se presenta el cuerpo docente, los fondos para investigaciones, proyectos e investigaciones de la misma universidad, sus centros de estudios y estadísticas.

Más específicamente es posible encontrar investigaciones en Chile y las instituciones y programas que otorgan fondos para la investigación, Institutos de Investigaciones y Academias de investigación. El slogan de esta pestaña es "La investigación en la Universidad C muestra grandes avances".

En esta misma línea el espacio de asuntos internacionales muestra cuáles son las posibilidades de estudiar en el extranjero, convenios internacionales y becas.

Notas al margen señala el portal respecto al vínculo entre comunidad y empresa en la cual destaca el laboratorio de ensayo de materiales, el centro de servicios empresariales, la clínica jurídica de la universidad, el centro de asistencia psicológica y estudios, el instituto de estudios y gestión pública, el instituto internacional para el desarrollo y el museo de la educación básica chilena.

Paralelamente se destacan un conjunto de centros: el centro de estudios del patrimonio, el centro de estudios arquitec- 
Los Sitios Web de las Universidades Privadas de Santiago en el marco de la Sociedad de la Información

tónicos, urbanísticos y del paisaje, el centro latinoamericano de documentación pedagógica, el centro de microempresas, entre otros.

En el link relacionado con la biblioteca se encuentra el catálogo electrónico y un programa de base de datos y documentación on-line (Pro Quest). Sumado a todas las encuestas que ha realizado el centro de estudios sociales y opinión pública de la universidad.

El website cuenta con un programa denominado Universidad C21, a través del cual alumnos y académicos tienen acceso a un Campus Virtual llamado Red-Campus, el cual ofrece una variedad de servicios y datos de interés relativos a todo el período. Solicitud de Apelación, Manual de Ayuda, Administración Docente Manual, etc.

La página contiene una aplicación especial denominada Google-Universidad C la cual es una herramienta electrónica que amplía y potencia los canales de comunicación de los alumnos a través de una cuenta de correo especial interactiva e interconectada.

\subsubsection{Publicidad y propaganda en el sitio web}

La Universidad C en el portal web se da a conocer a través de las diversas actividades que actualmente está realizando por áreas temáticas, situando el logo de Universidad Acreditada en la parte superior derecha de la página virtual.

En términos generales el portal, otorga relevancia a las noticias y académicos de prestigio que dictan charlas en las diversas facultades, aunque estas noticias se renuevan con gran frecuencia. Muestra mediante links adjuntos vínculos abocados al análisis y estudios y realización permanente de seminarios.

En la parte izquierda del website se comentan separadamente las actividades que actualmente esta desarrollando en cada una de las facultades, siendo posible acceder fácilmente a cada 
una de ellas; conocer sus carreras, autoridades, posgrados y cursos.

El slogan que se encuentra presente para publicitar el ingreso a la universidad es "Camina hacia tu futuro". En tanto la palabra clave de su publicidad es: Acreditada.

\subsection{Universidad D}

La Universidad D, no se encuentra acreditada y fue fundada en el 2006.

\subsubsection{Misión y visión}

Según su portal, la Universidad D está abocada a ofrecer una formación profesional integral de excelencia, con sentido ético, que propicia el interés por la promoción del bienestar social, la formación permanente, la adquisición y construcción de nuevos conocimientos e innovación en los distintos ámbitos del desarrollo a nivel nacional e internacional.

La Universidad D se propone formar profesionales involucrados con las redes del conocimiento, el manejo del idioma inglés, las nuevas tecnologías y la comunicación globalizada, para que sus estudiantes sean capaces de insertarse en el mundo laboral, a través de organizaciones públicas o privadas, a nivel local o en los nuevos mercados internacionales.

La Universidad D, aspira abarcar las principales áreas del saber, para llegar a constituir una institución con capacidad de interlocución con otros centros de estudio, capaz de aportar en la divulgación de la cultura y contribuir en el conocimiento y desarrollo de la ciencia y la tecnología.

\subsubsection{Estructura de la página web}

En la parte superior del portal se puede acceder a intranet, admisión 2009, profesionales bilingües, recursos bibliográficos, método Wall Street, programa de formación y testimonios de los alumnos de las diversas carreras que imparte la universidad D. 
Los Sitios Web de las Universidades Privadas de Santiago en el marco de la Sociedad de la Información

$\mathrm{Al}$ acceder a cada una de las facultades que tiene la universidad $\mathrm{D}$, aparece una presentación del decano sobre la facultad y las noticias pertinentes a la casa de estudios, pudiendo acceder mediante pestañas a cada una de las carreras que se imparte por facultad. Específicamente al interior de los links de cada carrera se encuentra una breve descripción de éstas, el perfil profesional del alumno y el campo ocupacional pertinente a esa carrera.

El portal contiene un vínculo de entrevista on-line con un cuestionario de postulación a la universidad, al mismo tiempo que una sección multimedia en la cual se publicita a la universidad D a través del formato Youtube.

El portal publicita los diversos convenios institucionales que existen con otras entidades públicas y privadas y un convenio exclusivo de biblioteca que tiene con un conocido preuniversitario de la Región Metropolitana.

La página web de la universidad $\mathrm{D}$ es austera, poco dinámica pero con información precisa respecto a su contenido, no utiliza grandes recursos tecnológicos y es tendiente a mezclar texto con información.

Su sistema de admisión funciona mediante consultas que pueden realizar los alumnos que desean ingresar a la universidad en la página web.

\subsubsection{Publicidad y propaganda en el sitio web}

La universidad D, en el tono del desarrollo de su website, no presenta una estrategia manifiesta de publicidad, aun cuando se puede identificar dos conceptos que intenta desarrollar la página: 1) La universidad $D$ es parte de una red educacional que tiene sus orígenes desde 1978;2) La ventaja comparativa que tiene esta universidad es generar profesionales bilingües.

Las Palabras clave posibles de identificar en su publicidad son: "Nuevos desafios", "Nuevos profesionales". 


\subsection{Universidad E}

La Universidad E no se encuentra acreditada, fue fundada en 1990 el y cuenta con un total de 3.302 alumnos.

\subsubsection{Misión y visión}

Según su portal, la Universidad E es una institución de Educación Superior que emerge desde procesos de reconstrucción de la sociedad civil chilena a comienzos de los años 90 como expresión del mundo alternativo. Su misión es contribuir al cambio cultural, socialmente sustentable, mediante la institucionalización, en el ámbito de las Ciencias Sociales, de una práctica universitaria innovadora que integre en un nudo inextricable tres dimensiones estratégicas: formación, investigación e intervención socio-comunitaria. Sus principios y valores aseguran un énfasis práctico en la propuesta formativa donde el trabajo en terreno adquiere una absoluta centralidad en las organizaciones curriculares de las distintas carreras. La visión publicitada busca contribuir a la formación integral de personas, a una sociedad más justa, solidaria y sustentable, a la paz mundial y a la construcción de una nueva civilización pluralista y de progreso; busca integrar saberes teóricos y prácticos, científicos y espirituales, intelectuales y emocionales, racionales e intuitivos. La Universidad E pretende, mediante un proceso de continua e intensa búsqueda, llegar a ser un centro de irradiación intelectual y cultural con un compromiso muy claro y definido con los principales desafíos que enfrenta hoy nuestra sociedad: el deterioro ambiental; la pobreza y la exclusión social; y la pérdida del sentido de la vida y de las cosas.

\subsubsection{Estructura de la página web}

El sitio web utiliza el sistema de links para acceder a cada una de los apartados del portal. Específicamente es posible encontrar tópicos como: admisión, carreras, programas especiales de titulación académica, postgrados, docencias, direcciones de asuntos estudiantiles, biblioteca, investigaciones y publicaciones, exten- 
Los Sitios Web de las Universidades Privadas de Santiago en el marco de la Sociedad de la Información

sión, ex alumnos y programas internacionales. Según el portal, los mejores libros de desarrollo humano, cambio de paradigma, ciencias sociales, ética, nuevas tendencias, psicología, geografía, política, pueblos originarios, entre otras materias, son parte de los textos publicados por la Editorial Universidad E, y es posible informarse sobre ellos en el link "libros publicados". La política de publicaciones de la universidad es una de sus grandes prioridades, lo que se demuestra en que se ha alzado como la universidad privada que editó la mayor cantidad de libros el año 2006, y la cuarta incluidas las universidades del Consejo de Rectores. En el año 2007 incrementó sus títulos aproximadamente en un 20\%. También la Editorial Universidad E, cuenta con importantes revistas académicas con sus respectivos enlaces electrónicos y links de publicaciones recientes.

La biblioteca es concebida por esta universidad como un componente fundamental para el desarrollo de las coherencias pedagógicas y como un sostén esencial de la vida académica y del desarrollo global de la institución, integrándose como un ente activo dentro de su comunidad.

Paralelamente en el portal es posible encontrar un motor de búsqueda para las publicaciones de esta universidad y el acceso a enlaces de interés de web social interactiva tales como Facebook, fliker, Myspace, fotolog, Twister y postcad.

\subsubsection{Publicidad y propaganda en el sitio web}

El portal se publicita mediante el sello "Una Universidad a Escala Humana" y en función de eso el proceso de admisión se presenta de la siguiente forma: "En la era de las TIC es importante contar con una plataforma Web amigable, que permita a nuestros alumnos conocernos y saber un poco más de nuestra historia y del quehacer universitario de la Universidad E. En estos 20 años de historia, donde se ha construido un proyecto educativo basado en la calidad académica y la libertad de expresión de nuestros jóvenes, te invitamos a visitarnos y a conocer un poco más de una 
Universidad distinta, que te entregará un sello que permitirá tu reconocimiento donde vayas como parte de la comunidad E."

Del mismo modo, para cada presentación de carrera utiliza en su portada una imagen de sus alumnos sumado a: una presentación genérica de ésta, el estilo formativo correspondiente, la metodología de enseñanza utilizada; puntualizando cuáles son sus ventajas respecto de otras universidades, su enfoque específico, el campo de ejercicio laboral, el perfil del estudiante y su malla curricular.

Una particularidad que destaca el website es la relevancia del ciclo común que se fundamenta principalmente en la actualización curricular, a partir de los criterios emergentes en el mundo de la Educación Superior.

La principal tarea del Ciclo Común es dirigir los procesos académicos de formación básica y transversal en coordinación con las diferentes unidades académicas. La actual propuesta del Ciclo Común tiende a complementar el currículum de la especialidad de cada Carrera, para lograr así los objetivos educacionales propios de la Universidad E y entregar, en sintonía con otro tipo de acciones que la UB impulse, el sello distintivo de esta casa de estudios a los egresados.

Los conceptos claves que destacan en su publicidad son: "Universidad a escala humana".

\subsection{Universidad F}

La Universidad F, no se encuentra acreditada, fue fundada en 1993 y cuenta con un total de alumnos de 6.800.

\subsubsection{Misión y visión}

Según el portal, la Universidad F es una corporación de derecho privado autónoma, sin fines de lucro que, en conjunto con las demás universidades, está llamada a cumplir la misión genérica de ser Institución de Educación Superior, atendiendo los in- 
Los Sitios Web de las Universidades Privadas de Santiago en el marco de la Sociedad de la Información

tereses y necesidades del país, a través de la docencia, en forma preponderante, y propendiendo a la investigación, extensión y la asistencia técnica a través de una vinculación con las organizaciones y comunidad en general, con el propósito de contribuir al enriquecimiento, conservación y transmisión de la cultura. La misión fundamental de la universidad F es preparar y proporcionar al país profesionales capaces de servir a la sociedad desde su actividad particular, en un entorno o ambiente informático y que, como personas, se destaquen por sus capacidades de emprender, desarrollando sus acciones dentro de los valores de nuestra cultura judeocristiana occidental. La formación como profesionales se funda en tres pilares, ellos son: la información, los valores y el espíritu emprendedor.

\subsubsection{Estructura de la página web}

El sitio web de esta universidad en la parte superior contiene las opciones de e-room, e-learning, biblioteca, posgrado, diplomados, capacitación, extensión, académica y financieras, relaciones internacionales y PIA.

Muestra las diversas carreras que se imparten en la universidad, el perfil profesional de los egresados, las sedes, sus aranceles y fotografías de las respectivas autoridades académicas; sus formas de financiamiento y sus mallas curriculares.

Posee un apartado para e-learnig donde se puede ingresar a clases a distancia y una modalidad de tipo presencial pero en la cual es posible cursar asignaturas en UFvirtual.

\subsubsection{Publicidad y propaganda en el sitio web}

El portal contiene elementos publicitarios aunque de manera discreta. La organización de la información y los datos corporativos se encuentran estructurados de manera escasamente llamativa, no profundizando en un mayor grado de información para el usuario.

Las palabras clave de su publicidad son: "El futuro está a tu alcance". 


\section{Conclusiones}

De lo expuesto en las secciones anteriores, relacionado con las características de los 24 sitios web de las universidades privadas de la Región Metropolitana, se deduce un conjunto de tendencias principales que pueden resumirse en los siguientes puntos:

a) Se observa un interés manifiesto en explicitar en la web la identidad institucional de la Universidad. A través de un conjunto de rasgos propios, ideas, valores y fines que le dan la razón de ser a la universidad expresada en su misión, así como el camino o rumbo que enfatiza, expresado habitualmente en su visión.

b) Se constata una tendencia a incluir en los respectivos sitios web aspectos publicitarios. Estos contenidos están destinados a públicos externos e internos con propósitos, diseños y mensajes diferenciados de tipo promocional, en especial para potenciales postulantes, y obtener aparentemente la "fidelización" de los actuales estudiantes.

c) Existe una dedicación, inversión, cuidado técnico, estético y planificación general progresiva de los sitios web de las universidades privadas. En prácticamente la totalidad de los casos analizados, se percibe una clara y manifiesta preocupación por la calidad de la estructura, elementos técnicos, renovación y actualización de la información que es seleccionada e incorporada al portal institucional de cada Universidad.

d) Se observa escaso desarrollo, interconexión e integración con los procesos de enseñanza-aprendizaje e investigación. Las actividades que utilizan e integran tecnologías de la información en entornos virtuales $u$ otras modalidades innovativas de índole pedagógica, si se llevan a cabo al interior de las universidades, se encuentran escasamente representadas en los respetivos portales.

e) Prevalecen en los sitios las funciones de difusión e información institucional. Si bien las páginas web se encuentran en una fase que aún no amplía el conjunto de actividades uni- 
Los Sitios Web de las Universidades Privadas de Santiago en el marco de la Sociedad de la Información

versitarias a una gran escala, existe una fuerte presencia del nivel de difusión de información, por sobre las posibilidades de acción e integración con los procesos formativos, de extensión e investigación fundamentales de la universidad.

f) Se detecta una tendencia a la difusión académica aunque con alcance limitado. Este aspecto se ve demostrado en la presencia de recursos destinados a la colocar a disposición contenidos bibliográficos, conferencias, documentos de utilidad para diversos usuarios, aunque con un fuerte predominio hacia los públicos internos (necesidad de claves, intranet, etc.). Las posibilidades de interacción con otros públicos y la comunidad son restringidos y escasos.

g) Existe un alto grado de control de la información de los sitios. Se constata una fuerte presencia de las directrices de las esferas más importantes de cada universidad. Ello se expresa en la estructura de las Intranet, las informaciones organizadas por facultades, y principales dependencias de la organización y el bajo desarrollo de recursos web 2.0, que adquieren, por sus características, un alto grado de independencia de las políticas institucionales.

h) Los sitios web expresan escasa vinculación interinstitucional. Este aspecto se ve reflejado en los sitios en relación con aspectos significativos del quehacer universitario. Si bien muchos sitios contienen información al respecto, ella está sobre todo centrada en posibles becas, continuidad de cursos internacionales o actividades puntuales pero no reflejan consolidación en los procesos universitarios fundamentales de formación, extensión e investigación.

Estas tendencias predominantes presentes en el contenido y arquitectura de los sitios web de las universidades privadas de la Región Metropolitana hasta el año 2008, parecen estar influidas por un conjunto de aspectos tanto nacionales como internacionales de distinta índole.

En términos macrosociales dan cuenta de un proceso considerablemente similar de ajuste germinal que podemos denominar 
adaptación de baja intensidad, teniendo en cuenta las dimensiones que considera el despliegue de la sociedad de la información y las exigencias que implican para el sistema universitario y sus funciones predominantes. Entre los múltiples aspectos influyentes se aprecian dos ejes fuertes que pueden ayudar a interpretar esta modalidad adaptativa que se observa como producto de fuerzas predominantemente externas más que como un proceso interno de distinción y diferenciación. Se reconocen en ese sentido mecanismos y códigos extraídos del sistema económico así como ajustes que buscan satisfacer las demandas y marcos normativos derivados desde el Estado.

Se constata así considerable homogeneidad en las estrategias institucionales adoptadas en el uso de los portales web que revelan respuestas adaptativas de orden más bien pragmático, que no han logrado procesar comprensivamente las repercusiones de los cambios, ajustándose, a nuestro parecer, a requerimientos fundamentalmente de corto y mediano plazo relacionados con presiones de mercado y exigencias de normativas públicas.

La incorporación de nuevas tecnologías aún no ingresa como parte constituyente de los procesos centrales de sus actividades docentes de investigación y extensión universitaria, concentrándose sobre todo en la informatización administrativa y el uso acotado de tecnologías multimedia que complementa una docencia que se asemeja todavía mayoritariamente a formatos clásicos más que a formas verdaderamente innovativas de enseñanzaaprendizaje.

En ese sentido, sobresalen en los sitios web institucionales especialmente aspectos relacionados con la búsqueda de posicionamiento, identificación institucional, promoción de rasgos propios y logros en términos de prestigio, difusión de actividades para públicos internos y cuidado estético. Ello da testimonio de un esfuerzo de las universidades privadas por aprovechar de la mejor forma este recurso durante el último lustro, si bien se ha canalizado fundamentalmente en la dimensión informativo- 
Los Sitios Web de las Universidades Privadas de Santiago en el marco de la Sociedad de la Información

promocional de relación con el público interno y externo a la universidad.

La incorporación profunda de la tecnología de la información a los procesos más centrales del quehacer universitario se encuentra aún en una fase preliminar. La articulación de los sitios web con los procesos pedagógicos de enseñanza-aprendizaje, se evidencia de una manera débil, prevaleciendo la incorporación de aspectos fundamentalmente de administración de la docencia, que en todo caso muestran avances significativos en los últimos años. Por otra parte, la posible apertura de los materiales docentes y difusión más abierta en la línea de los Open Course Ware, es prácticamente inexistente, encontrándose los materiales académicos en la gran mayoría de los casos protegidos en los ambientes de usuarios autorizados en la intranet de cada universidad.

La articulación nacional e internacional de redes, en el marco de colaboraciones interuniversitarias o de intercambio con el sector empresarial se ve poco reflejada en las respectivas páginas. En ese sentido, los sitios web al menos, no están constituyendo una herramienta que potencie de manera clara la interacción articulada para el desarrollo de la investigación, el desarrollo de intercambios con el mundo empresarial y la anhelada innovación que requiere el modelo de desarrollo informacional.

Lo anterior no quiere decir que no se observe un influjo de las tendencias internacionales. Por el contrario, se aprecia una influencia evidente, aunque difícil de delinear en términos precisos, derivada de la visibilidad, tendencias e importancia que han adquirido los respectivos sitios de las principales universidades del mundo, las que vienen perfeccionando sus portales web desde hace más de veinte años. Es posible reconocer claras similitudes en la arquitectura de los sitios web y en determinadas propuestas estéticas. Los formatos, distribución de la información, ordenamiento y aspectos estéticos generales se asemejan con las páginas web de las principales universidades norteamericanas como 
Princeton o Harvard, mientras que los aspectos relacionados con la información relativa a la vida universitaria, tienden a acercarse mucho más a los sitios web de las casas de estudios españolas más reconocidas, que incluyen frecuentemente herramientas de la web 2.0, tendencia poco observada en las páginas norteamericanas.

Una influencia local reconocible ha tenido que ver con el hecho de que las universidades públicas y más antiguas del país activaran, desarrollaran y alimentaran sus respectivos sitios web también desde finales de la década de los ochenta.

Otra influencia en los contenidos observados de manera homogénea, derivó muy probablemente de la normativa que enfatizó la CNAP (Comisión Nacional de Acreditación de Pregrado, actual CNA), hace más de una década, particularmente en lo relativo a la necesidad de explicitar la misión y visión de las universidades en orden a estructurar de manera lógica los procesos de acreditación que se buscaba implementar. Se advierte especialmente durante los últimos cuatro o cinco años, un reconocimiento mucho más explícito de los compromisos doctrinarios con determinadas tendencias o vinculaciones confesionales de las universidades que las que ocurrían en el pasado reciente. Ello declara formalmente hechos y adscripciones ampliamente conocidas tanto por los que estudian y trabajan en dichas casas de estudio como en la opinión pública general. A nuestro entender constituye un indicador sano de transparencia y madurez del sistema en esta dimensión.

Por otra parte, la fuerte competencia presente en el mercado de la educación superior incrementada en los últimos años, evidentemente ha marcado una orientación fundamental hacia el alumnado, que constituye el principal actor al cual es necesario acceder y "fidelizar". Esta tendencia se ve reflejada en un lenguaje con énfasis publicitario que se evidencia en variados elementos de los sitios de las universidades privadas observadas. Al uso a modo de promoción inicial relacionado con argumentos vinculados con el tamaño de la universidad en tanto cantidad de 
Los Sitios Web de las Universidades Privadas de Santiago en el marco de la Sociedad de la Información

alumnos, el alcance territorial o la calidad de infraestructura disponible, se observa una creciente tendencia a destacar las redes internacionales, la calidad de los alumnos y académicos.

Adicionalmente la obtención de la acreditación institucional, el período de vigencia alcanzado y las áreas consideradas en el proceso, que por disposición de la propia CNA debe figurar de manera clara en todas las comunicaciones públicas de las universidades, se han constituido en factores de promoción de particular relevancia especialmente por aquellas casas de estudios que han obtenido resultados más favorables.

En consecuencia, se observa un escenario digital en pleno desarrollo representado por páginas web de universidades privadas que presentan un considerable isomorfismo, que han alcanzado un interesante despliegue técnico-estético, que ponen fuerte énfasis en aspectos de autopromoción e imagen corporativa, pero que poseen aún alcance limitado respecto de otras tareas fundamentales del mundo universitario.

Existe por tanto un espacio importante para el crecimiento y profundización de esta herramienta tecnológica en términos de su integración con muchos recursos académicos, de investigación, extensión y el establecimiento de redes y vínculos inter-institucionales. Queda el desafío para que estas dimensiones sean incrementadas en el futuro cercano, pues la dinámica exhibida y el ritmo de adaptación de este recurso demuestra por parte de las universidades privadas una alta movilidad y capacidad de respuesta a los cambios y exigencias del entorno.

De igual modo, es posible esperar en los próximos años un rápido desarrollo de plataformas e-learning, que aún se encuentran poco extendidas, teniendo en cuenta la relevancia que adquiere la educación de adultos, la formación continua y la necesidad de mantener los vínculos con la importante masa de egresados que han acumulado las universidades. Este capital les permitiría una diversificación potencial de los servicios educacionales que hasta el momento se han concentrado en los jóvenes egresados de la 
enseñanza media y muy poco en los adultos jóvenes profesionales, que demandarán necesidades formativas, de especialización, actualización y de certificación de competencias cada vez con mayor intensidad.

Lo que parece claro, dado el curso de los acontecimientos en el marco de las evoluciones que vive la universidad contemporánea, es el hecho de que las estructuras de la educación superior que aún conservan rasgos incluso de la tradición medieval, resultan crecientemente inapropiadas en entornos altamente contingentes. Respuestas adaptativas de baja intensidad, que resulten en adecuaciones pragmáticas como las observadas en los sitios web caracterizados, pero que no sean capaces de enfrentar los cambios reintegrando las funciones universitarias a las operaciones centrales de un nuevo modo, podrían resultar insuficientes frente a los grandes desafíos derivados de la sociedad de la información.

\section{Bibliografía}

Adams, Jonathan y Eveland, Vicki. "Marketing online degree programs: How do tradicional-residential programs complete? Journal of Marketing for higher education, Vol. 17, N¹, 2007.

Brunner, José Joaquín. “El cambio en los sistemas de educación superior. Apuntes sobre el caso chileno", en Boletín N²5 del Proyecto Principal de Educación, Santiago, 1991.

"Educación Superior y Desarrollo en el nuevo contexto latinoamericano". http://mt.educarchile.cl/mt/jjbrunner/archives/2005/08/educacion_super.html

Estado, Mercado y Conocimiento: Políticas y Resultados en Educación Superior Chilena 1960-1990. Santiago, Ed. FLACSOChile, 1992.

La Educación Superior en Chile: 1960-1990, Evolución y Políticas. Oferta y demanda de profesionales y técnicos en Chile. El rol de la Información pública. Ed. Ril, Santiago, 2004.

http:/ / mt.educarchile.cl/mt/jjbrunner/archives/2005/08/ nuevas_demandas.html

Globalización y el futuro de la educación: tendencias, desafíos, estrategias. Promedlac, UNESCO, Santiago, 2001. 
Los Sitios Web de las Universidades Privadas de Santiago en el marco de la Sociedad de la Información

Tendencias Recientes de la Educación Superior a Nivel Mundial (2005). http://mt.educarchile.cl/mt/jjbrunner/archives/2005/08/tendencias_reci.html

Prometeo de visita en América Latina. http://mt.educarchile. cl/mt/jjbrunner/archives/2007/04/prometeo_de_vis.html

El Proceso de Bolonia en el horizonte latinoamericano: límites y posibilidades. Revista de Educación, Número especial Ministerio de Educación y Ciencia, Madrid, 2008.

Brunner, José, Joaquín y Daniel Uribe. Mercados Universitarios: El Nuevo Escenario de la Educación Superior, Editorial Universidad Diego Portales, Santiago, 2007.

Bueno, Eduardo. "La tercera misión de la universidad: el reto de la transferencia del conocimiento". Revista de investigación en gestión de la innovación y la tecnología, número 4, 2007.

Cantero, Alberto. "Adecuación de la Universidad al Proceso de Globalización", en Brovetto, Jorge y Rojas Miguel (eds.). Universidad Iberoamericana, Globalización e Identidad, Madrid, Ed. CEXESI, 1999.

Cantero, Carlos (ed.). Sociedad de la Información, Santiago, Universidad Tecnológica Metropolitana, 2003.

Castells, Manuel. La Era de la Información: Economía, sociedad y Cultura, Vol I, La Sociedad Red, Madrid, Ed. Alianza, 1997.

La Galaxia Internet. Reflexiones sobre Internet, empresa y sociedad, Madrid, 2001, Plaza \& Janés Editores, 2001.

Globalización, Desarrollo y Democracia: Chile en el Contexto Mundial, Santiago, Fondo de Cultura Económica, 2005.

Donoso, Roberto. Mito y Educación. Impacto de la Globalización en la Educación en Latinoamérica, Buenos Aires, Ed. Espacio, 1999.

Etzkowitz, H. "The future of the and the university of the future: evolution of ivory tower to entrepreneurial". Research policy, 29 (2), 2000.

Fernández, Enrique. “Perspectivas de futuro de las universidades privadas fundadas con posterioridad a 1980". En J.J. Brunner y C. Peña (editores). Reforma de la Educación Superior. Ediciones Universidad Diego Portales, Santiago, 2009.

Ferraté, Gabriel. "Universidad y nuevas tecnologías: El camino hacia la hiperuniversidad" en Porta Jaume y Lladonosa Manuel (co- 
ords.), La Universidad en el Cambio de Siglo, Madrid, Ed. Alianza, 1998.

Flecha, Ramón y Tortajada, Lolanda. "Retos y salidas educativas en la entrada del siglo", en Inbernón, Francisco (Coord.) La Educación en el Siglo XXI. Los retos del futuro inmediato, Barcelona, Biblioteca Aula, 2002.

Gimeno, Sacristán, José. “La Educación que tenemos, la educación que queremos", en Inbernón, Francisco (Coord.), La Educación en el Siglo XXI. Los retos del futuro inmediato, Barcelona, Biblioteca Aula, 2002.

Imbernón, Francisco (coord.). La Educación en el Siglo XXI. Los retos del futuro inmediato. Barcelona Ed. Graó, 2002.

Larraín, Jorge. ¿América Latina Moderna?, Globalización e Identidad, Santiago, Ed. LOM, 2005.

Lechner, Norbert. "Tres Formas de Organización Social", Santiago, Revista de la CEPAL, 1997.

Luhmann, Niklas. Sistemas Sociales: Lineamientos para una Teoría General, México, Editorial Alianza, 1991.

Luhmann, Niklas. Sociología del Riesgo, México, Universidad Iberoamericana, 1992.

Luhmann, Niklas. Teoría de la Sociedad y Pedagogía, Barcelona, Ed. Paidós, 1996.

Luhmann, Niklas. Confianza, Universidad Iberoamericana, Barcelona Anthropos, 1996.

Luhmann, Niklas. Organización y Decisión. Autopoiesis, acción y entendimiento comunicativo, Barcelona, Ed. Anthropos, 1997.

Luhmann, Niklas . Complejidad y Modernidad. De la Unidad a la Diferencia, Valladolid, Ed. Trotta, 1998.

Marqués, Pere. "Impacto de las TIC en Educación: Funciones y Limitaciones", Textos electrónicos Universidad Autónoma de Barcelona, Departamento de Psicología Aplicada, 2008. http:/ / dewey. uab.es/pmarques/siyedu.htm

Mascareño, Aldo. Diferenciación Funcional en América Latina: Los contornos de una sociedad concéntrica y los dilemas de su transformación", Revista Persona y Sociedad, Santiago, abril, 2000.

Moran, L. y Myringer, B. Flexible learning and university change. En Harry, 
Los Sitios Web de las Universidades Privadas de Santiago en el marco de la Sociedad de la Información

K. (ed.): Higher Education Through Open and Distance Learning. London: Routledge, 1999.

Pedreño, Andrés. La universidad en la sociedad del siglo XXI. Fundación Santander Central Hispano, Madrid, 2001.

Perinat, Adolfo. Conocimiento y Educación Superior, Nuevos Horizontes para la Universidad del Siglo XXI, Barcelona, Ed. Paidós, 2004.

Riveros, Luis. Mis visiones sobre Educación. Propuestas para un Debate, Santiago, Ed. Universitaria, 2002.

Rodríguez, Darío y Torres Nafarrate, Javier. "Introducción a la Teoría de la Sociedad de Niklas Luhmann", Ed. Herder, México, 2008.

Rodríguez, Roberto. Educación Superior en el Mercado, Configuraciones emergentes y nuevos actores, CLACSO, Buenos Aires, 2003.

Rojas, Miguel. "La función intelectual de la Universidad: ¿una responsabilidad abandonada?, en Brovetto, Jorge y Rojas Miguel (eds), Universidad Iberoamericana, Globalización e Identidad, Madrid, Ed. CEXESI, Madrid, 1999.

Salinas, Jesús. "La integración de las TIC en las instituciones de educación superior como proyectos de innovación educativa". Universidad de las Islas Baleares, 2000. http:/ /www.uninorte.eu.co/ congresog10/conf/06-la-Integración-de-las-TIC-en-las-Instituciones.pdf

"Redes y desarrollo profesional del docente: Entre el dato serendipity y el foro de trabajo colaborativo". Rev. Profesorado (Univ. de Granada), 2 (1).

http://www.uib.es/depart/gte/docente.html, 1998.

Nuevos ambientes de aprendizaje para una sociedad de la información. Revista Pensamiento Educativo, 20. Pontificia Universidad Católica de Chile, Santiago, 1997.

San Martín, Patricia. "Hipertexto. Seis propuestas para este milenio". Ed. La Crujía, Buenos Aires, 2005.

Zabalza, Miguel. La Enseñanza Universitaria. El escenario y sus protagonistas, Madrid, Narcea Editores, 2002.

\section{Artículos de Prensa}

Diario EL MERCURIO. "Publicidad universitaria: Planteles superiores se juegan "todo" antes de fin de año", Santiago, viernes 23 de noviembre de 2007. 